\title{
GEOGRAPHICAL VARIATION OF PHOTOPERIODIC ADULT DIAPAUSE IN DROSOPHILA AURARIA
}

\author{
NAOTAKA MINAMI AND MASAHITO T. KIMURA \\ Zoological Institute, Faculty of Science, Hokkaido University, \\ Sapporo, Hokkaido 060
}

Received February 18, 1980

\begin{abstract}
The variation of photoperiodic adult diapause was studied in Drosophila auraria strains originating in Japan at latitudes from 33.8 to $43.1^{\circ} \mathrm{N}$. All the differently-located geographical strains showed a photoperiodic diapause. The critical daylength of these strains fell between 12 and $14 \mathrm{~h}$. The diapause intensity increases with an increase in latitudes. The duration of diapause was shorter at a photoperiod of 12 or $6 \mathrm{~h}$ than at one of 10 or $8 \mathrm{~h}$ in all the strains. This is because the photoperiod of 12 or $6 \mathrm{~h}$ is less effective as a stimulus for the maintenance of diapause.
\end{abstract}

\section{INTRODUCTION}

Diapause is an ecogeographic character and correlates closely with altitude and latitude (Masaki 1967; Danilevsky et al. 1970; Tauber and Tauber 1972; Bradshaw and Lounibos 1977; Lumme and Oikarinen 1977). In general, populations of geographically widespread insect species from higher latitudes enter diapause earlier than those found in lower latitudes. To accomplish this, northern forms from the Northern Hemisphere enter diapause in response to longer day lengths, i.e., northern forms show a longer critical photoperiod which ensures the timely initiation of diapause in response to long day lengths in late summer at high latitudes (cf. Danilevsky et al. 1970). Danilevsky et al. also gave examples of species in which the more northern forms experience deeper diapause than the southern ones. The difference in diapause intensity correlates well with the duration and severity of winter conditions at the different latitudes.

Drosophila auraria Peng is distributed in Japan, Korea and China. Minami et al. (1979) showed the Sapporo population of this species display a reproductive diapause controlled by photoperiod and temperature. Here we report the geographic variation of diapause in this species.

\section{MATERIALS AND METHODS}

Material was obtained from five localities in Japan: Sapporo (SP strain; $43.1^{\circ} \mathrm{N}$ in latitude), Akita (AK strain; $39.7^{\circ} \mathrm{N}$ ), Urawa (UR strain; $\left.35.8^{\circ} \mathrm{N}\right)$, Chiba $(\mathrm{CH}$ strain; 
$35.6^{\circ} \mathrm{N}$ ), and Matsuyama (two strains, MA-1 and MA-2; $33.8^{\circ} \mathrm{N}$ ). The SP strain originated from several field-collected females, but the other strains were from a single female. These strains were maintained under diapause-preventing conditions (continuous illumination, $23^{\circ} \mathrm{C}$ ) for months or years until the present experiment.

Apparatus and rearing conditions were similar to those described by Minami et al. (1979). To study the photoperiodic response, animals were reared from the egg stage through the adult stage under three photoperiodic conditions, LD 10:14 (10 h light: $14 \mathrm{~h}$ dark), LD $12: 12$, and LD $14: 10$, and the proportion of diapausing females was examined at 8 th, 16th, and/or 24th days after eclosion. For the SP strain, the diapause was examined at additional ages $(32,40,48$, and 64 days after eclosion) under four photoperiodic conditions, LD $6: 18$, LD $8: 16$, LD $10: 14$ and LD $12: 12$. In this experiment, animals were cultured at $18^{\circ} \mathrm{C}$ before eclosion and $15^{\circ} \mathrm{C}$ and/or $18^{\circ} \mathrm{C}$ after eclosion, because a temperature of $18^{\circ} \mathrm{C}$ resulted in a higher larval and pupal viability than one of $15^{\circ} \mathrm{C}$. Temperatures of 15 and $18^{\circ} \mathrm{C}$ before eclosion differ little in their effects on diapause (Kimura and Minami unpubl.).

The diapause intensity of these geographical strains was measured by $\mathrm{T}_{50}$ (number of long daylengths required to terminate diapause in half of a sample population; cf. Bradshaw and Lounibos 1977). Samples of 20 to 50 newly emerged diapausing females (reared under $\mathrm{LD} 10: 14,18^{\circ} \mathrm{C}$ ) were first exposed to $0,2,4,6, \ldots, 16$ long days (LD $14: 10,15^{\circ} \mathrm{C}$ ), and then to $16,14,12,10, \ldots, 0$ short days (LD $10: 14,15^{\circ} \mathrm{C}$ ), respectively. After a total of 16 exposures, the percentage of diapausing females was examined and then plotted against the number of long days exposed. The $50 \%$ intercept was read directly.

The developmental stage of the ovaries was examined by dissection under a binocular microscope, and the females with undeveloped ovaries were assumed to be in a reproductive diapause (cf. Minami et al. 1979).

\section{RESULTS AND DISCUSSION}

The variation in the proportion of diapausing females was controlled by four factors: temperature, age, photoperiod, and the geographical origin of the strains. The proportion of diapausing females was lower when they were reared at $18^{\circ} \mathrm{C}$ throughout their entire life than when they were transferred to $15^{\circ} \mathrm{C}$ at the time of adult eclosion (Fig. 1). This was considered to be due to that the diapause ends earlier at higher temperatures at the adult stage (Kimura and Minami unpubl.). Fig. 2 shows the effect of age on the proportion of diapause in the SP strain. The proportion decreased as age increases under various photoperiods as $6,8,10$, and $12 \mathrm{~h}$. In the other strains, the proportion was also lower at 24th day than 8th day after eclosion (Fig. 1, b and c).

When cultured at $15^{\circ} \mathrm{C}$, the proportion of females with undeveloped ovaries was low at LD $14: 10$ even at 8 th day after eclosion in all strains, but not at LD $10: 14$ and LD $12: 12$. This suggests that their critical daylength fell between LD $12: 12$ and LD $14: 10$. Under short daylengths, the duration of diapause was modified by a kind 

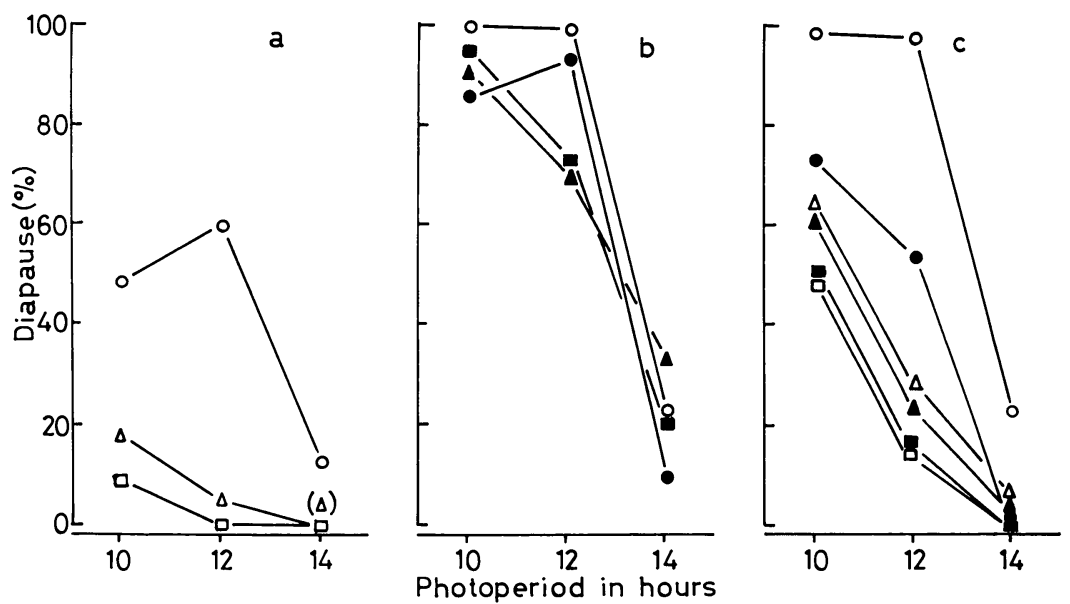

Fig. 1. Photoperiodic response curves of geographical strains of D. auraria: Sapporo $(\mathrm{O}-\mathrm{O})$, Akita $(-\bullet)$, Urawa $(\Delta-\Delta)$, Chiba $(\Delta-\Delta)$, Matsuyama-1 ( $\square-\square)$, and Matsuyama-2 (-—). Flies were cultured at $18^{\circ} \mathrm{C}$ for 16 days after eclosion (a), at $15^{\circ} \mathrm{C}$ for 8 days (b), and at $15^{\circ} \mathrm{C}$ for 24 days (c). About 30 females were examined for each point.

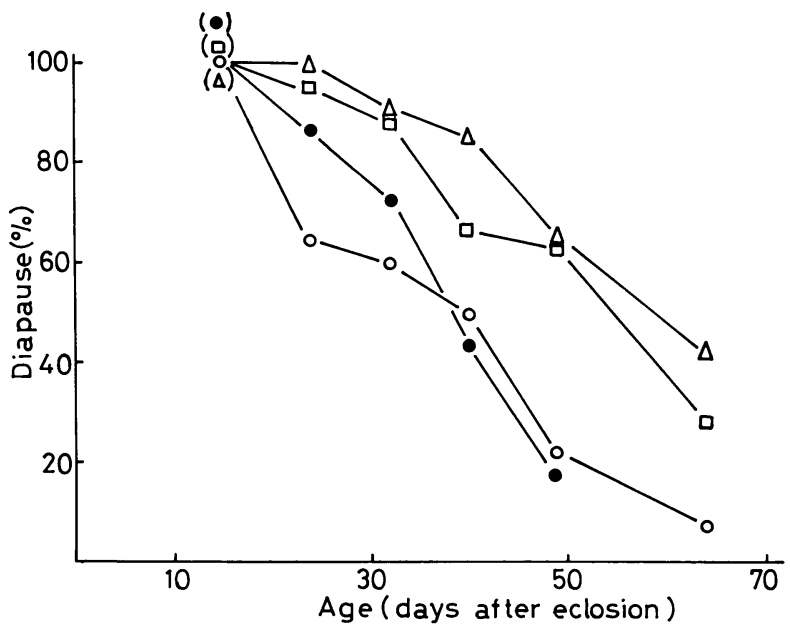

Fig. 2. Diapause percentages of the Sapporo strain of D. auraria when cultured under LD $6: 18(\bigcirc-O)$, LD $8: 16(\triangle-\triangle)$, LD $10: 14(\square-\square)$, and LD $12: 12(-\bullet)$ conditions. About 30 females were examined for each point.

of photoperiods experienced. The proportion of diapausing females decreased earlier at LD $6: 18$ and LD $12: 12$ than LD $8: 16$ and $\mathrm{LD} 10: 14$ at $15^{\circ} \mathrm{C}$ in the SP strain (Fig. 2). In the other strains, the proportion of diapausing females also decreased earlier at LD $12: 12$ than LD $10: 14$ (Fig. 1, c).

The effectiveness of different photoperiods as a stimulus for the maintenance of 
Table 1. Diapause percentages of females transferred into various photoperiodic conditions

\begin{tabular}{cccccc}
\hline \hline $\begin{array}{c}\text { Photoperiod } \\
\text { before } \\
\text { transfer }\end{array}$ & LD $6: 18$ & LD $8: 16$ & LD $10: 14$ & LD $12: 12$ & LD $14: 10$ \\
\hline LD $6: 18$ & 50.0 & 72.3 & 68.2 & 49.4 & 29.2 \\
LD $8: 16$ & 57.1 & 86.7 & 66.7 & 57.1 & 21.9 \\
LD $10: 14$ & 74.5 & 71.5 & 63.0 & 44.0 & 7.2 \\
LD $12: 12$ & 32.1 & 79.2 & 66.7 & 42.9 & 17.6 \\
\hline
\end{tabular}

About 30 females were examined for each value.

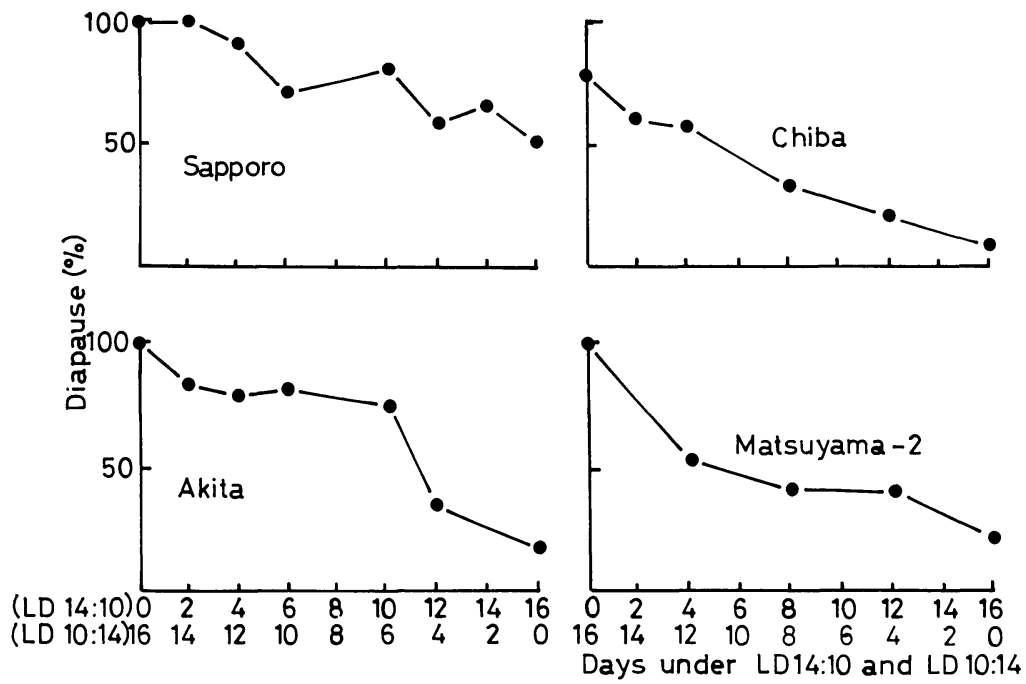

Fig. 3. Percentages of diapausing females at 16 th day after the photoperiodic treatment of various combinations of LD $14: 10$ and LD $10: 14$.

diapause was studied with the SP strain. Diapausing females cultured under different photoperiods by the age of 24 days after eclosion were transferred to various kinds of photoperiodic conditions, and diapause was examined 16 days after the transfer. In this experiment, the flies were also cultured at $18^{\circ} \mathrm{C}$ before eclosion and $15^{\circ} \mathrm{C}$ after eclosion. Table 1 shows results. Females transferred to a LD $14: 10$ condition showed the termination of diapause. In contrast, the diapause was maintained in about $80 \%$ or $65 \%$ levels when flies were transferred to a LD $8: 16$ or LD $10: 14$ condition respectively. Females transferred to LD $6: 18$ and LD $12: 12$ conditions showed the intermediate percentage of diapause. Thus, diapausing females regarded different photoperiods ranging from $6 \mathrm{~h}$ to $14 \mathrm{~h}$ of light in different ways in the course of diapause maintenance. Tauber and Tauber (1973) observed a similar phenomenon in Chrysopa carnea which quantitatively responded to various daylengths in the course of diapause termination.

Figure 3 shows the geographical variation of the diapause intensity against the longday treatment which at last breaks the state of diapause. The Sapporo strain was 


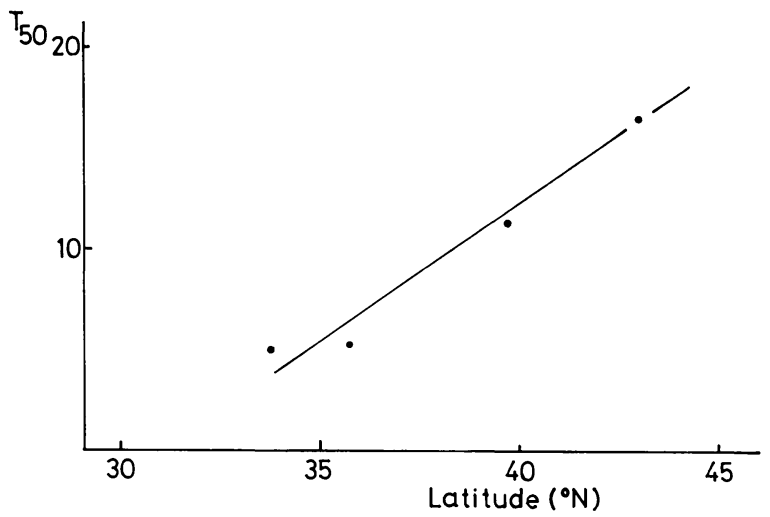

Fig. 4. Relationship between diapause intensity as measured by $T_{50}$ and the latitude where the materials originated.

most resistant to the treatment but the Chiba and Matsuyama strains were sensitive, and the Akita strain was intermediate. From Fig. 3, $T_{50}$ was regarded as 16.0 for the SP strain, 11.1 for $\mathrm{AK}, 5.2$ for $\mathrm{CH}$ and 5.0 for MA-2 respectively. The diapause intensity measured by $T_{50}$ correlates highly with latitudes of strains originated (Fig. 4):

$$
\mathrm{T}_{50}=1.245^{\circ} \mathrm{N} \text { Lat. }-38.047
$$

This equation was sufficient to explain $97 \%$ of the variation in $\mathrm{T}_{50}$ which was observed among these geographical strains $(r=0.986$, d.f. $=2)$. The earlier end of diapause in the southern strains (Fig. 1, c) would be due to their less intense diapause.

The geographical differentiation of diapause intensity observed in this study could be a result of adaptation to local climates. The Sapporo population of this species, however, is not completely adapted to the climate of Sapporo (Iwao et al. 1980). If females of this species oviposit eggs after mid September, the eggs do not grow to adult before the arival of winter in Sapporo. Therefore, it is meaningless for females to grow their ovaries after mid September. The optimal timing of diapause is, then, considered in early September. In fact, many of temperate species which display an adult diapause enter diapause in late August or early September in Sapporo (Watabe and Beppu 1977; Watabe 1977; Toda and Kimura 1978). However, D. auraria enters diapause in late September in Sapporo. Iwao et al. (1980) assumed that the maladaptation of this species is due to gene flow from southern populations or to the newness of the colonization of this species in Hokkaido. It is still not known whether this species adapts to southern climates or not. Adaptation of this species to local climate and the meaning of cline in the diapause intensity must be studied in future from the point of the seasonal occurrence of diapause at different latitudes.

\section{ACKNOWLEDGMENTS}

We wish to express our sincere thanks to Dr. Eizi Momma for his advice in the course of the study and further to Messrs. M. J. Toda, H. Watabe, N. Ichijô, Y. Sado, 
A. Yamamoto, N. Kôyama, and O. Enomoto for their providing the materials.

\section{LITERATURE CITED}

Bradshaw, W. E., and L. P. Lounibos, 1977, Evolution of dormancy and its photoperiodic control in pitcher-plant mosquitos. Evolution 31: 546-567.

Danilevsky, A. S., N. I. Goryshin, and V. P. Tyshchenko, 1970 Biological rhythms in terrestrial arthropods. Ann. Rev. Entomol. 15: 201-244.

Iwao, Y., M. T. Kimura, N. Minami, and H. Watabe, 1980 Bionomics of Drosophilidae (Diptera) in Hokkaido. III. Drosophila auraria and D. biauraria. Kontyû 48: 160-168.

Lumme, J., and A. Oikarinen, 1977 The genetic basis of the geographical variable photoperiodic diapause in Drosophila littoralis. Hereditas 86: 129-142.

Masaki, S,. 1967 Geographic variation and climatic adaptation in a field cricket (Orthoptera: Gryllidae). Evolution 21: 725-741.

Minami, N., M. T. Kimura, and N. Ichijo, 1979 Physiology of reproductive diapause in Drosophila auraria: photoperiod and temperature as controlling factors. Kontyû 47: 244-248.

Tauber, M. J., and C. A. Tauber, 1972 Geographic variation in critical photoperiod and in diapause intensity of Chrysopa carnea (Neuroptera). J. Insect Physiol. 18: 25-29.

Tauber, M. J., and C. A. Tauber, 1973 Quantitative response to daylength during diapause in insects. Nature 244: 296-297.

Toda, M. J., and M. T. Kimura, 1978 Bionomics of Drosophilidae (Diptera) in Hokkaido. I. Scaptomyza pallida and Drosophila nipponica. Kontyû 46: 83-98.

Watabe, H., 1977 Drosophila survey of Hokkaido, XXXIV. Seasonal variations of body color of Drosophila testacea. J. Fac. Sci. Hokkaido Univ. (VI-Zool.) 21: 21-30.

Watabe, H. and K. Beppu, 1977 Drosophila survey of Hokkaido, XXXIII. Ovarian development of Drosophila in relation to wild population. J. Fac. Sci. Hokkaido Univ. (VI-Zool.) 20: 611620. 